\begin{tabular}{|c|c|c|}
\hline & Int.J.Curr.Microbiol.App.Sci (2021) 10(11): 56-66 & \\
\hline & $\begin{array}{l}\text { International Journal of Current Microbiology and Applied Sciences } \\
\text { ISSN: 2319-7706 Volume } 10 \text { Number } \mathbf{1 1} \mathbf{( 2 0 2 1 )} \\
\text { Journal homepage: http://www.ijcmas.com }\end{array}$ & 30 \\
\hline $\begin{array}{l}\text { EXCELLENT } \\
\text { PUBLISHERS }\end{array}$ & & \\
\hline
\end{tabular}

Original Research Article https://doi.org/10.20546/ijcmas.2021.1011.008

\title{
Genetic Diversity Studies in Mungbean (Vigna radiata L. Wilczek) Germplasm
}

\author{
Reshmi Jahan Mohammed*, L. Prasanthi and Lakshminarayana R. Vemireddy
}

Department of Genetics and Plant breeding, S.V. Agricultural College, 1 RARS, Tirupathi- 517502, Andhra Pradesh, India

*Corresponding author

\begin{tabular}{|c|}
\hline Keywords \\
\hline $\begin{array}{l}\text { Vigna radiata, } \\
\text { Genetic } \\
\text { divergence, } \\
\text { D2 analysis, } \\
\text { Cluster } \\
\text { analysis }\end{array}$ \\
\hline Article Info \\
\hline $\begin{array}{l}\text { Received: } \\
04 \text { October } 2021 \\
\text { Accepted: } \\
30 \text { October } 2021 \\
\text { Available Online: } \\
10 \text { November } 2021\end{array}$ \\
\hline
\end{tabular}

\section{Keywords}

Vigna radiata, Genetic divergence, D2 analysis, Cluster 10 November 2021

\section{A B S T R A C T}

An investigation was carried out to estimate the genetic divergence for twenty characters in 50 genotypes of greengram [Vigna radiata (L.) Wilczek] using Mahalanobis's $\mathrm{D}^{2}$ statistic and total of eight clusters were formed. The highest number of genotypes were found in cluster II containing sixteen genotypes followed by cluster I with thirteen genotypes, cluster IV with ten genotypes, cluster VI with five genotypes, cluster VIII with three genotypes and clusters III, V and VII with only one genotype. Highest intra-cluster distance was observed for cluster IV (87.54) and lowest intra cluster distance was observed for clusters III, V and VII. The highest inter-cluster distance was observed between cluster IV and VIII (285.11), while the lowest inter cluster distance was observed between cluster VI and VII (251.29). Among the characters studied, phenols content contributed the maximum (32.57\%) towards the diversity. The genotypes present in the clusters V (COGG-13-19) and VII (LGG-544) showed high seed yield performance so, cross obtained between these genotypes will give better performance for yield. The genotypes in the cluster VI (GGG-1, GGG-1-1, IPM-2-14, WGG-42, EC-396117) and cluster III (AGG-35) exhibited resistance to YMV. Hence, the crosses among cluster V, VII, VI and III would give high seed yield along with YMV disease resistance.

\section{Introduction}

Greengram (Vigna radiata (L.) wilczek), $2 n=22$, Fabaceae is one of the most important edible food legumes of Asia widely cultivated and consumed throughout India (Datta et al., 2012). It is one of the important pulse crop because of its adaptation to short duration of growth, soil fertility, low water requirement and is favoured for consumption due to its easy digestibility and low production of flatulence (Shil and Bandopadhya, 2007). Average protein content in greengram seeds is around $24 \%$. The protein is rich in lysine, an amino acid which is predominantly deficient in cereal grains (Baskaran et al., 2009). Grafius (1978) suggested that there may not be genes for yield per se but rather for the 
various components, the multiplicative interactions of these components result in the artifact of yield. In any program aimed at genetic improvement of the yield, genetic diversity is prerequisite. The yield of mungbean has not increased substantially due to dearth of sufficient genetic diversity in the germplasm for desirable traits used for crop improvement (Skrotch and Nienhuis, 1995). Hence, it is essential to have knowledge on variability of different characters for crop improvement. Crop improvement is largely depending on the amount of genetic variability subsisting among the selected populations. Genetic diversity is one of the key factors and it is mandatory in any hybridization program. Acquiring of desirable recombination can be possible only by the inclusion of diverse parents in the hybridization program (Yimram et al., 2009). Study of genetic diversity is critical for breeders for better understanding of genetic and evolutionary relationships among populations, to select germplasm in a more systematic and efficient way and to advance the strategies to incorporate useful diversity in their breeding programs (Lavanya et al., 2008). The crosses between the parents with maximum genetic diversity are generally the most amenable for genetic improvement (Arunachalam, 1981).

\section{Materials and Methods}

The present experiment was carried out at dry land farm of Regional Agricultural Research Station, Tirupati during rabi, 2018. The experimental material comprised of 50 greengram genotypes, which were raised in Randomised Block Design, each entry being sown in three rows of $4 \mathrm{~m}$ length with a spacing of $30 \times 10 \mathrm{~cm}$. Twenty traits viz., plant height, days to $50 \%$ flowering, days to maturity, number of primary branches per plant, number of clusters per plant, number of pods per plant, pod length, number of seeds per pod, harvest index, hundred seed weight,
SPAD chlorophyll meter reading, seed yield per plant, leaf hairiness, leaf thickness, leaf amino acid content, leaf phenol content, leaf protein content, leaf sugar content, leaf reducing sugar content and YMV disease score were recorded from randomly selected plants in each of the genotypes per replication, except days to 50 per cent flowering and days to maturity which were noted on plot basis. The statistical analysis for divergence was worked out according to $\mathrm{D}^{2}$ statistic given by Mahalanobis (1936). Grouping of genotypes into different clusters was done by using Tocher's method as described by Rao (1952). The criterion used in clustering, by the method was that any two variables belonging to the same cluster should atleast, on an average show a smaller $\mathrm{D}^{2}$ values of the combinations of each genotype arranged in increasing (ascending) order of their magnitudes in a tabular form as described by Singh and Choudhary (1977).

\section{Results and Discussion}

To test the significant differences between the genotypes for all the characters based on their pooled effects, Wilks ' $\wedge$ ' (statistic) criterion was used. Analysis of variance indicated the significant pooled effect of all the characters studied between different genotypes. Hence, further analysis was carried out to estimate the $\mathrm{D}^{2}$ values.

\section{Clusters composition}

The fifty greengram genotypes were grouped into eight clusters. Distribution of genotypes into each of eight clusters was presented in Table1 and Figure 1. Cluster II had maximum genotypes as it contains sixteen genotypes. Thirteen genotypes were present in cluster I, ten genotypes in cluster IV, five genotypes in cluster VI, three genotypes in cluster VIII and clusters III, V and VII contained each of only one genotype. The pattern of group 
constellations indicated that significant variability was present among the genotypes as observed from the clusters. Cluster II originating from different places indicating that there was no parallelism between geographic distributions and clustering pattern of genotypes. Similar findings were reported by Rahim (2010) and Henry and Mathur (2007). This kind of genetic diversity was recorded among the genotypes belonging to the same geographic origin might be due to difference in adoption, selection criteria, selection pressure and environmental condition.

\section{Intra and inter-cluster average distance}

The inter and intra cluster $\mathrm{D}^{2}$ and $\mathrm{D}$ values among eight clusters were given in Table 2 and Figure 2.

Average intra-cluster $\mathrm{D}^{2}$ values ranged from zero (clusters III, V and VII) to 87.54 (cluster IV). Among them, cluster IV had the largest intra cluster distance (87.54), while the clusters III, V and VII have recorded zero value as they included only one genotype. Maximum inter cluster distance was found between cluster IV and cluster VIII (285.11) followed by between clusters VI and VII (251.29) while the lowest inter cluster distance was recorded between cluster III and cluster V (89.77).

\section{Cluster means for yield, leaf morphological and biochemical characters}

The cluster means of twenty characters were presented in Table 3. Considerable differences between clusters means- were noticed for most of the characters studied. The genotype present in cluster VII was maximum in plant height $(39.45 \mathrm{~cm})$, while the genotypes in cluster VI were short in plant height (21.09 $\mathrm{cm})$. Early flowering was noticed in cluster V and VI (30 days) while the genotypes included in cluster IV showed delayed flowering (39.03 days). Days to maturity varied from 62.67 (cluster VI) to 71.27 days (cluster IV). Similarly, branches per plant ranged from 0.24 (clusters IV) to 2.11 (cluster VIII), whereas number of clusters per plant plotted between 4.52 (cluster VI) to 7.67 (cluster III). The genotype in cluster $\mathrm{V}$ recorded highest for pod length $(7.69 \mathrm{~cm})$ and the genotype in cluster VII recorded lowest for pod length $(6.56 \mathrm{~cm})$. Number of seeds per pod ranged from 8.82 (cluster VI) to 10.23 (cluster II). Genotype in cluster VII had high number of pods per plant (20.43) while in genotypes in cluster VI had low number of pods per plant (9.75). The seed yield per plant ranged from $3.98 \mathrm{~g}$ (cluster I) to $8.77 \mathrm{~g}$ (cluster V). Highest harvest index was observed in cluster VIII (37.66 \%) while the lowest harvest index was observed in cluster III (28.60\%). Highest 100 seed weight was recorded in cluster VI (4.64 g) while the lowest was recorded in clusters III (3.00 g).

The cluster mean for SPAD chlorophyll meter reading was high in cluster III (45.73) and low in cluster II (43.90). Highest mean for leaf thickness was recorded in clusters I, III, IV, V VI $(0.28 \mathrm{~cm})$, while the lowest was recorded in cluster VII $(0.24 \mathrm{~cm})$. The genotypes in cluster VI were recorded highest leaf hairiness (39.31) whereas the cluster VIII was recorded lowest leaf hairiness (32.89).

The cluster mean for amino acid content was high in clusters II and VII $\left(0.78 \mathrm{mg} \mathrm{g}^{-1}\right)$, while the lowest was recorded in cluster III $(0.56 \mathrm{mg}$ $\left.\mathrm{g}^{-1}\right)$. The genotype in cluster III was recorded highest phenol content $(20.63 \%)$, whereas the lowest was recorded in cluster II $(13.50 \%)$.

Cluster V was exhibited highest sugar content (22.47 $\mathrm{mg} \mathrm{g}^{-1}$ ), while the cluster I was exhibited lowest sugar content (15.29 $\left.\mathrm{mg} \mathrm{g}^{-1}\right)$. Reducing sugar content mean was recorded highest in cluster VII $\left(9.64 \mathrm{mg} \mathrm{g}^{-1}\right)$, while the lowest was recorded in cluster VI $\left(6.96 \mathrm{mg} \mathrm{g}^{-}\right.$ 
$\left.{ }^{1}\right)$. The cluster mean for protein content was highest in cluster VII $\left(1.07 \mathrm{mg} \mathrm{g}^{-1}\right)$, while the lowest in cluster III $\left(0.72 \mathrm{mg} \mathrm{g}^{-1}\right)$. Yellow Mosaic Virus disease score was high in cluster $\mathrm{V}$ (4.67) and was low in cluster VI (0.93).

The study of cluster means for different characters disclosed the considerable differences among the clusters for all the characters studied. The genotypes in the cluster I exhibited low sugar content whereas, the genotypes in the cluster II exhibited low phenol content and high number of seeds per pod. Similarly, the genotype in cluster III recorded maximum number of clusters per plant, high phenol content, high SCMR and also low harvest index, low 100 seed weight, low amino acid content, low protein content and low YMV disease score.

The cluster IV exhibited delayed maturity, delayed flowering and low number of branches per plant. The genotype in cluster $\mathrm{V}$ recorded early flowering, high pod length, high seed yield per plant, high harvest index, high sugar content and high YMV disease score. Shorter plants, low number of clusters per plant, early maturity, low number of seeds per pod, low number of pods per plant, high 100 seed weight, low amount of reducing sugars and high leaf hairiness was recorded in cluster VI. The genotype in cluster VII exhibited taller plants, low pod length, high number of pods per plant, high amount of amino acid, reducing sugar and protein contents. The genotypes in cluster VIII recorded high number of branches per plant and low leaf hairiness. To generate a wide spectrum of variability, inter crossing among the genotypes from the clusters could be suggested followed by effective selection.

\section{Relative contribution of each character towards diversity}

The selection of parents mainly depends upon contribution of character towards divergence (Loganathan et al., 2001). Number of times that each of the 20 characters appeared in first rank and its per cent contribution towards diversity was presented in Table4 and Fig 3.

Among the characters studied, phenols content contributed the maximum (32.57\%) towards the diversity by taking first rank 399 times, followed by number of branches per plant $(21.22 \%)$ with 260 times ranked first and days to $50 \%$ flowering $(19.27 \%)$ with 236 times ranked first.

The characters viz., days to maturity $(7.84 \%)$ with 96 times ranked first, leaf thickness (5.96 $\%$ ) with 73 times ranked first, pod length (3.18 $\%)$ with 39 times ranked first, 100 seed weight $(2.61 \%)$ with 32 times ranked first contributed towards the diversity. Similarly, amino acid content contributed $(1.96 \%)$ with 24 times ranked first and YMV disease score $(1.47 \%)$ with 18 times ranked first contributed towards the divergence.

Sugar content $(0.73 \%)$ with nine times ranked first, seed yield per plant and protein content $(0.65 \%)$ with eight times ranked first, SPAD chlorophyll meter reading $(0.57 \%)$ with seven times ranked first, reducing sugars $(0.41 \%)$ with five times ranked first, plant height and number of seeds per pod $(0.33 \%)$ with four times ranked first, harvest index $(0.16 \%)$ with two times ranked first, and leaf hairiness contributed $(0.08 \%)$ with one time ranked first contributed minimum towards the divergence. 
Table.1 Cluster composition with 50 greengram genotypes (Tochers method)

\begin{tabular}{|c|c|c|}
\hline $\begin{array}{c}\text { Cluster } \\
\text { Number }\end{array}$ & $\begin{array}{c}\text { No. of genotypes } \\
\text { included in each cluster }\end{array}$ & Genotype(s) included \\
\hline I & 13 & $\begin{array}{c}\text { OBGG-56, OBGG-57, VGG-16-027, NVL-722, VGG-16-036, } \\
\text { OBGG-58, Panth Mung-5, COGG-13-39, Pusa-15161, VGG- } \\
\text { 14-001, VGG-15- 038, IPM-312-9, IPM-409-4. }\end{array}$ \\
\hline II & 16 & $\begin{array}{c}\text { TARM-1, VBN (Gg)-2, COGG-11-02, IGKM-0642, ADGG- } \\
\text { 13009, LGG-460, VGG-15-30, LGG-595-1, NRI Sakthi, } \\
\text { VGG-05-009, Pusa-9072, VGG-15-030-1, LGG-577, CO-6, } \\
\text { MGG-387, LGG-521 }\end{array}$ \\
\hline III & 1 & AGG-35 \\
\hline IV & 10 & LGG-594, LGG-574, LGG-595, VGG-10-008, LGG-596, \\
& & LGG-578, MGG-385, MGG-385-1, Pusavishal, NRI Amulya \\
\hline V & 1 & COGG-13-19 \\
\hline VI & 5 & GGG-1-1, GGG-1, IPM-2-14, WGG-42, EC-396117 \\
\hline VII & 1 & LGG-544 \\
\hline VIII & 3 & MGG-373, LGG-607, VGG-16-055 \\
\hline
\end{tabular}

Table.2 Intra cluster (diagonal) and inter - cluster distances for eight clusters in greengram

\begin{tabular}{|l|c|c|c|c|c|c|c|c|}
\hline & Cluster & Cluster & Cluster & Cluster & Cluster & Cluster & Cluster & Cluster \\
& $\mathbf{1}$ & $\mathbf{2}$ & $\mathbf{3}$ & $\mathbf{4}$ & $\mathbf{5}$ & $\mathbf{6}$ & $\mathbf{7}$ & $\mathbf{8}$ \\
\hline Cluster 1 & 67.83 & 134.33 & 90.90 & 141.25 & 101.31 & 108.85 & 217.56 & 212.44 \\
& $(8.24)$ & $(11.59)$ & $(9.53)$ & $(11.88)$ & $(10.07)$ & $(10.43)$ & $(14.75)$ & $(14.58)$ \\
\hline Cluster 2 & & 78.48 & 103.94 & 129.98 & 99.51 & 143.68 & 101.14 & 156.07 \\
& & $(8.86)$ & $(10.20)$ & $(11.40)$ & $(9.98)$ & $(11.98)$ & $(10.06)$ & $(12.49)$ \\
\hline Cluster 3 & & & 0.00 & 117.68 & 89.77 & 168.59 & 91.56 & 126.56 \\
& & & $(0.00)$ & $(10.85)$ & $(9.47)$ & $(12.98)$ & $(9.57)$ & $(11.25)$ \\
\hline Cluster 4 & & & & 87.54 & 172.46 & 186.67 & 156.52 & 285.11 \\
& & & & $(9.36)$ & $(13.13)$ & $(13.66)$ & $(12.51)$ & $(16.89)$ \\
\hline Cluster 5 & & & & & 0.00 & 105.03 & 136.32 & 107.22 \\
& & & & & $(0.00)$ & $(10.25)$ & $(11.68)$ & $(10.35)$ \\
\hline Cluster 6 & & & & & & 69.65 & 251.29 & 208.30 \\
& & & & & & $(8.35)$ & $(15.85)$ & $(14.43)$ \\
\hline Cluster 7 & & & & & & & 0.00 & 119.18 \\
& & & & & & & $(0.00)$ & $(10.92)$ \\
\hline Cluster 8 & & & & & & & & 84.19 \\
& & & & & & & & $(9.18)$ \\
\hline
\end{tabular}


Table.3 Cluster means for yield, leaf morphological and biochemical characters in 50 greengram genotypes

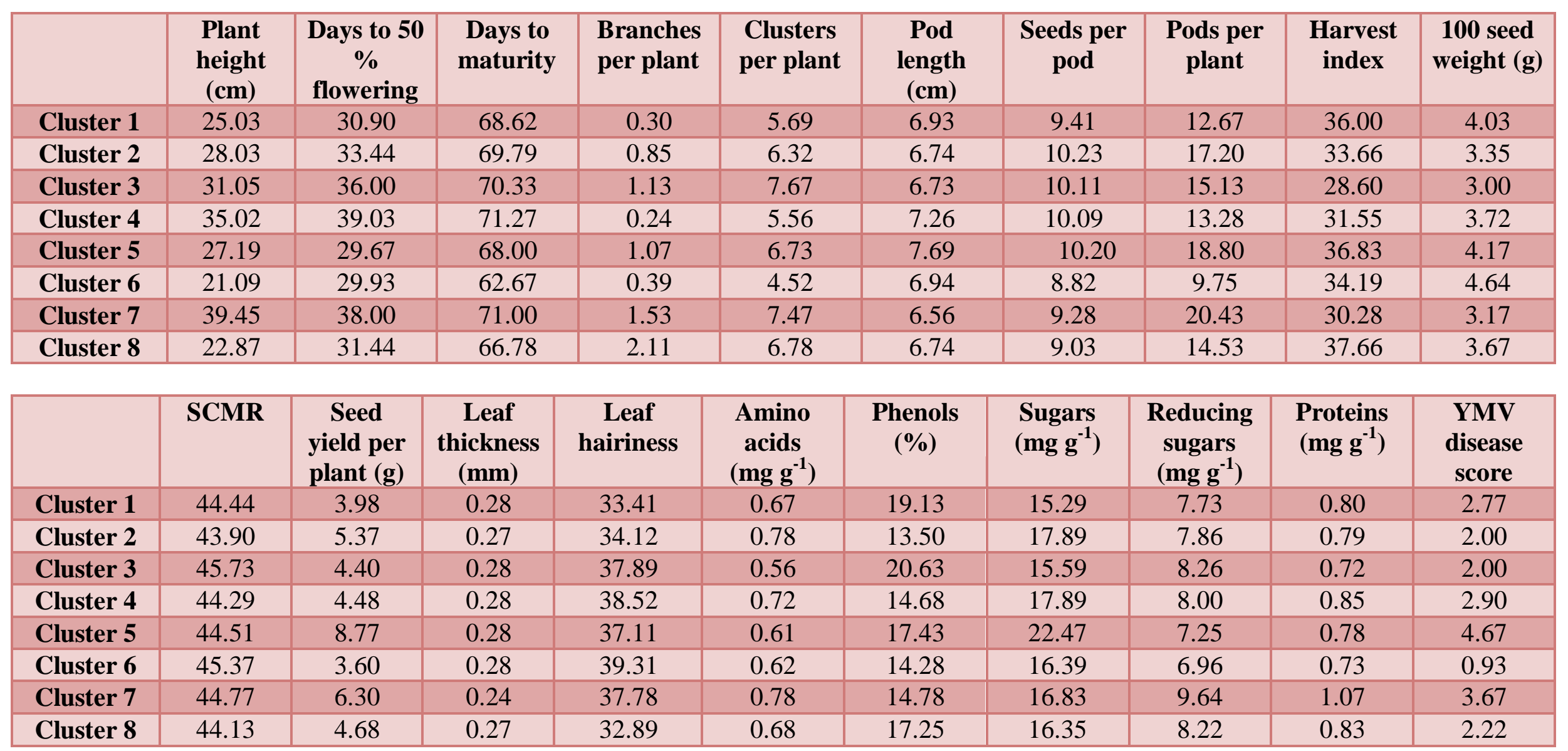


Table.4 Relative contribution of different characters to diversity in 50 greengram genotypes

\begin{tabular}{|c|c|c|c|}
\hline S.No & Characters & Times ranked first & Contribution \% \\
\hline $\mathbf{1}$ & Plant height $(\mathrm{cm})$ & 4 & 0.33 \\
\hline $\mathbf{2}$ & Days to 50\% flowering & 236 & 19.27 \\
\hline $\mathbf{3}$ & Days to maturity & 96 & 7.84 \\
\hline $\mathbf{4}$ & Number of branches per plant & 260 & 21.22 \\
\hline $\mathbf{5}$ & Number of clusters per plant & 0 & 0.00 \\
\hline $\mathbf{6}$ & Pod length (cm) & 39 & 3.18 \\
\hline $\mathbf{7}$ & Number of seeds per pod & 4 & 0.33 \\
\hline $\mathbf{8}$ & Number of pods per plant & 0 & 0.00 \\
\hline $\mathbf{9}$ & Seed yield per plant $(\mathrm{g})$ & 8 & 0.65 \\
\hline $\mathbf{1 0}$ & Harvest index (\%) & 2 & 0.16 \\
\hline $\mathbf{1 1}$ & 100 seed weight $(\mathrm{g})$ & 32 & 2.61 \\
\hline $\mathbf{1 2}$ & SCMR & 7 & 0.57 \\
\hline $\mathbf{1 3}$ & Leaf thickness (mm) & 73 & 5.96 \\
\hline $\mathbf{1 4}$ & Leaf hairiness & 1 & 0.08 \\
\hline $\mathbf{1 5}$ & Amino acids $\left(\mathrm{mg} \mathrm{g}^{-1}\right)$ & 24 & 1.96 \\
\hline $\mathbf{1 6}$ & Phenols $(\%)$ & 399 & 32.57 \\
\hline $\mathbf{1 7}$ & Sugars $\left(\mathrm{mg} \mathrm{g}^{-1}\right)$ & 9 & 0.73 \\
\hline $\mathbf{1 8}$ & Reducing sugars $\left(\mathrm{mg} \mathrm{g}^{-1}\right)$ & 5 & 0.41 \\
\hline $\mathbf{1 9}$ & Protein $\left(\mathrm{mg} \mathrm{g}^{-1}\right)$ & 8 & 0.65 \\
\hline $\mathbf{2 0}$ & YMV disease score & 18 & 1.47 \\
\hline
\end{tabular}


Fig.1 Dendrogram of 50 greengram genotypes obtained through Tocher's method of classification

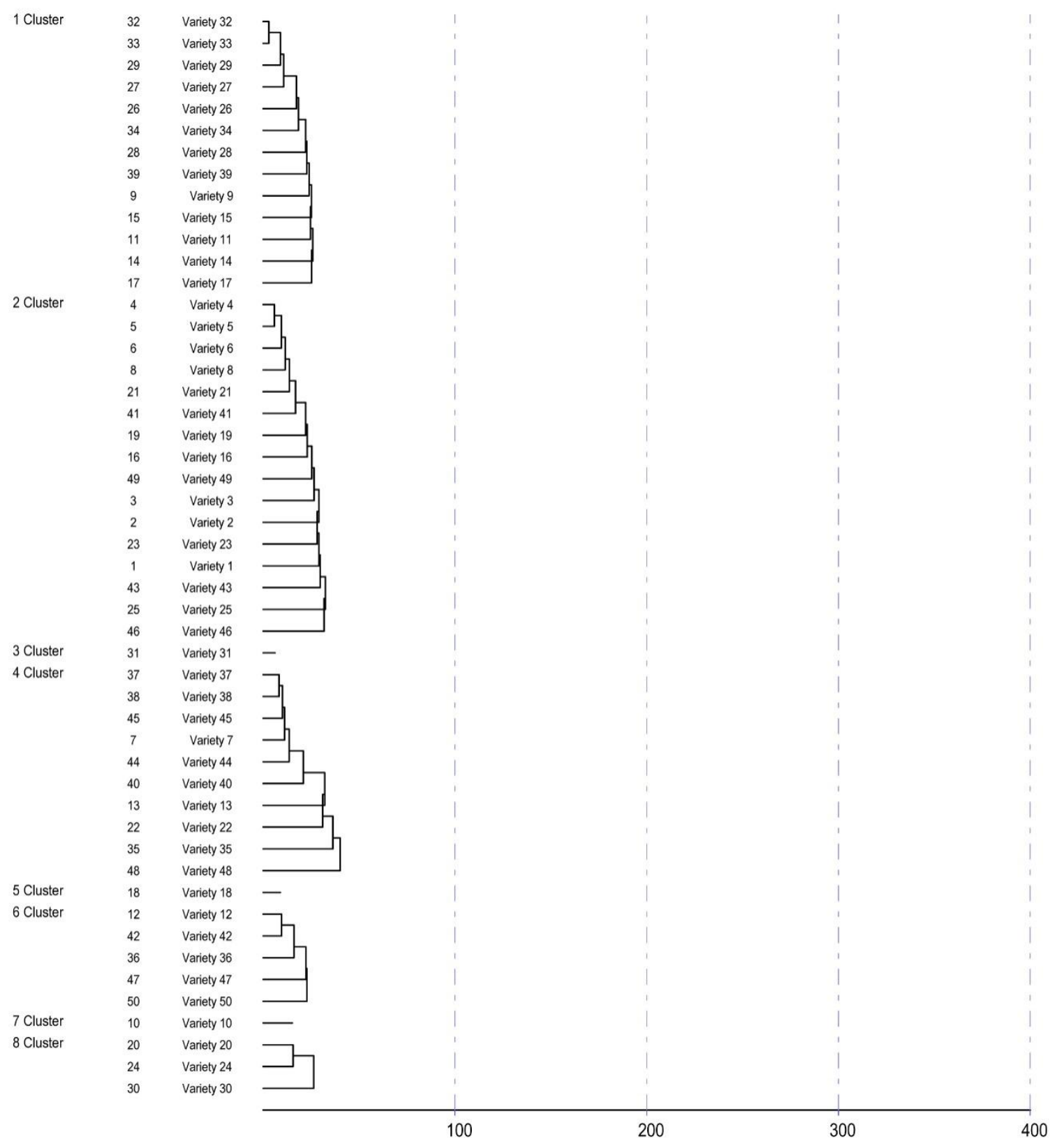


Fig.2 Intra-cluster (D) and inter-cluster distance $\left(\mathrm{D}^{2}\right)$ among eight clusters of greengram

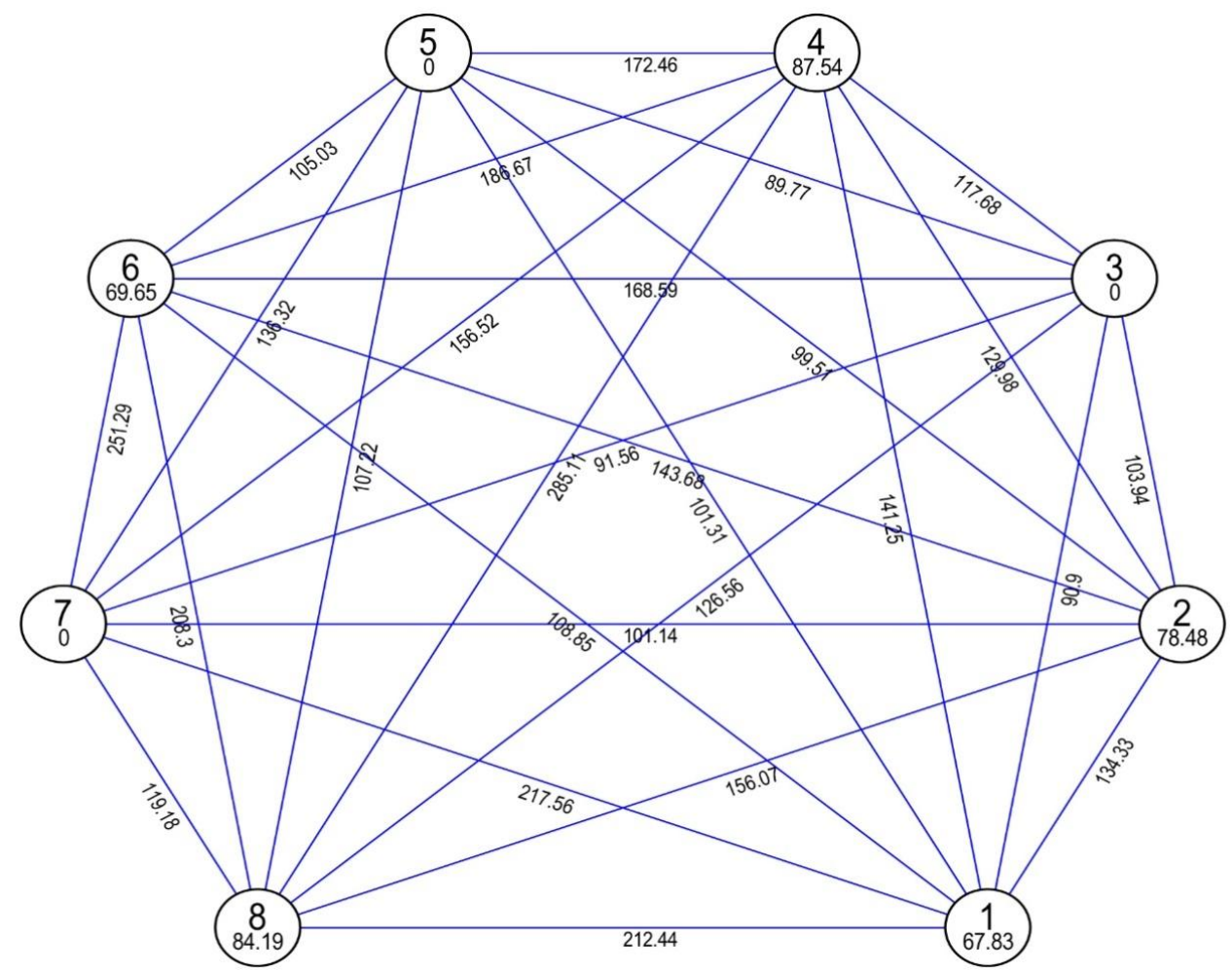

Fig.3 Relative contribution of different characters towards diversity

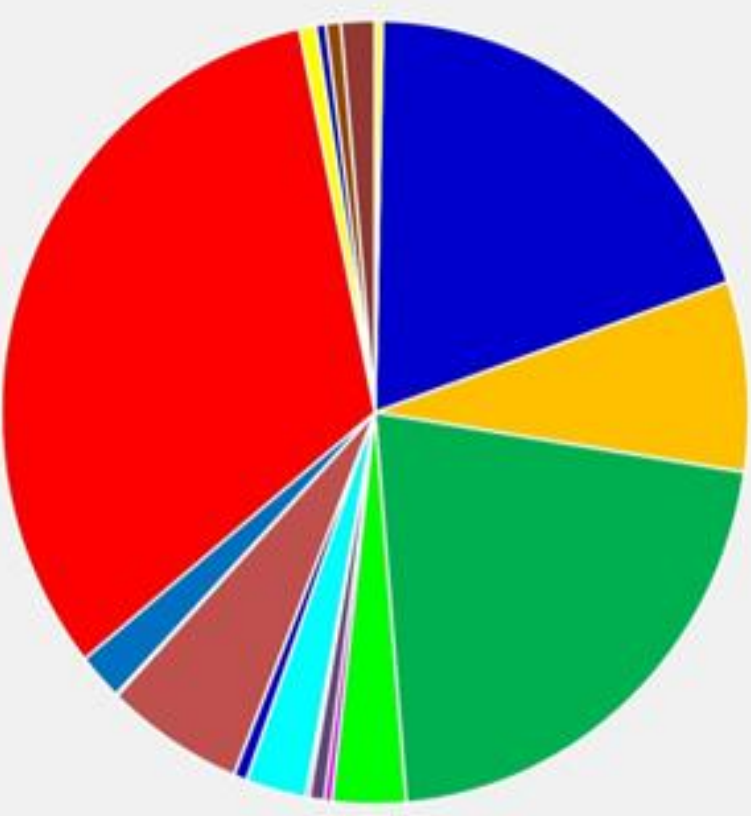

Past hecitutiont

- Oun to sos fowering

* Deys to muturity

* Nimber of primary branches per plane

- Muinder of cluater per plaes

stod length ion:

* mimber of vetediper pot

- Marinder of pods per plant

- Send yeld per plant in

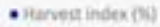

+ 300 uned weient id

- sovir

- inaf nicineis inesy

- irar haminess

- Amine scids incar 13

- Heveinisa

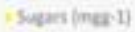

- Medueine nears inus-1)

- Priten (ras 1)

- Nuv docase seon 
On the contrary, number of pods per plant and number of clusters per plant had zero contribution towards genetic divergence. For crop improvement, the hybridization programme should consider the performance of genotypes and characters with maximum contribution towards divergence.

Out of eight clusters formed, cluster II contained highest number of 16 genotypes whereas III, V, VII contained only one genotype each (Table 2). Minimum intercluster distance was recorded between the cluster $\mathrm{V}$ and III suggesting the close relationship and similar magnitude for most of the characters of the genotypes in these clusters (Table 3). Maximum inter-cluster distance was recorded between cluster IV and cluster VIII (285.11) followed by the distance between cluster VI and cluster VII (251.29) were considered to be more divergent. The genotypes in these clusters can be utilized as divergent parents and crossing among these genotypes would be suggested to generate a wide range of variability for effective selection in improvement of various characters. The genotypes present in the clusters, V (COGG-13-19) and VII (LGG544) showed high seed yield performance so, cross obtained between these genotypes will give better performance for yield. The genotypes in the cluster VI (GGG-1, GGG-11, IPM-2-14, WGG-42, EC-396117) and cluster III (AGG-35) exhibited resistance to YMV. Hence, the crosses among cluster V, VII, VI and III would give high seed yield along with YMV disease resistance. Thus, superior segregants can be obtained by crossing of such genotypes as parents hybridization programmes. Maximum intercluster distances confirming the presence of diversity among clusters. Moll and Stuber (1971) suggested that crosses between divergent parents usually produced greater heterosis than those between closely related ones, whereas Arunachalam (1981) suggested that extreme divergence may not produce the high frequency of heterotic crosses.

The $\mathrm{D}^{2}$ analysis revealed the existence of considerable diversity among the genotypes of greengram studied and they were grouped into eight clusters. The characters viz., phenol content, number of branches per plant and days to $50 \%$ flowering contributed maximum towards genetic divergence. The maximum inter cluster distance was noticed between cluster IV and VIII, followed by between cluster VI and VII. Hence, genotypes viz., LGG-594, LGG-574, LGG-595, VGG-10-008, LGG-596, LGG-578, MGG-385, MGG-385-1, Pusavishal and NRI Amulya from the cluster IV, MGG-373, LGG-607, VGG-16-055 from the cluster VIII, GGG-1-1, GGG-1, IPM-2-14, WGG-42, EC-396117 from the cluster VI and LGG-544 from the cluster VII may be included in hybridization programme for obtaining superior and desirable recombinants.

\section{References}

Arunachalam V. 1981. Genetic distance in plant. Indian Journal of Genetics and Plant Breeding. 41: 226-236.

Henry A and. Mathur B K. 2007. Correlation studies of quality parameters, seed yield and maturity period in cluster bean. J. Arid Legumes, 5(1):70-74.

Loganathan P K, Saravanan and Ganesan J. 2001. Genetic analysis of yield and related components in green gram (Vigna radiata L.). Research on crops, 1:34-36.

Moll R H and Stuber C W. 1971. Comparisons of response to alternative section procedures initiated with two populations of maize (Zea mays). Crop Science. 11: 706-711.

Rahim M A. 2010. Genetic variability, character association and genetic divergence in mungbean (Vigna radiata L. Wilczek). Plant Omics. 3(1):1-6. 
Rao C R. 1952. Advanced statistical methods in biometrical research. John Wiley and Sons Inc. New York. pp: 357-363.

Singh R K and Choudhury B D. 1977. Biometrical methods in quantitative genetic analysis. Kalyani Publishers, Ludhiana, India pp: 304.

Skrotch P and Nienhuis J. 1995. Qualitative and quantitative characterization of
RAPD variation among snap bean (Phaseolus lanatus L.) genotypes. Theor. Appl. Genet. 91: 1086-1091.

Yimram T, Somta, P and Srinives P. 2009.

Genetic variation in cultivated mungbean germplasm and its implication in breeding for high yield. Field. Crop Res., 112:260-266.

\section{How to cite this article:}

Reshmi Jahan Mohammed, L. Prasanthi and Lakshminarayana R. Vemireddy. 2021. Genetic Diversity Studies in Mungbean (Vigna radiata L. Wilczek) Germplasm. Int.J.Curr.Microbiol.App.Sci. 10(11): 56-66. doi: https://doi.org/10.20546/ijcmas.2021.1011.008 